The bactericidal action of penicillin depends upon bacterial growth and any condition which is unfavourable for growth is likely to be antagonistic.

What is the best way to use penicillin in view of these problems? It would seem that answers to all of the questions posed above are needed before the most prudent use of penicillin can be achieved.

\section{REFERENCES}

Chatterjee, A. N., and Park, J. T. (1964), Proc. na丣 Acad. Sci. (Wash.), 51, 9.

Ito, E. and Strominger, J. L. (1963), J. biol. Chem 237, 2689.

JAWETZ, E., and GunNison, J. B. (1952), Antibiot and Chemother., 2, 243.

Meadow, P. M., Thompson, J. S., and Strominger J. L. (1964), Biochem. biophys. Res. Commur 14, 382 .

\title{
INTERPRETATION OF ASSAY VALUES
}

\author{
E. T. KNUDSEN
}

Beecham Research Laboratories, Brentford, Middlesex.

THE appearance of new antibiotics in everincreasing numbers demands a critical appraisal of the data usually presented relating to their therapeutic properties. Generally speaking, the common investigations undertaken to assess antibiotic potential are liable to a number of sources of error.

The investigations fall into five main groups:

1. In vitro activity studies (broth or serum).

2. Serum concentration determinations and "serum" antibacterial activity studies.

3. "Tissue" concentrations (animal or man).

4. Chemotherapeutic assessment in animals.

5. Clinical trials in man.

In vitro activity studies determine the minimum inhibitory concentration (M.I.C.) of an antibiotic for a given organism-the figure so obtained depends, among other factors, upon whether the determination is carried out in broth or in serum. The origin of the serum (whether human or animal) will influence the result as well as the concentration of the serum used in the determination $(40 \%, 60 \%, 80 \%$, $95 \%$ ).

Table I shows the M.I.C.s of a penicillin for an organism obtained in broth culture and in $95 \%$ human serum.

TABLE I

Minimum Inhibitory Concentrations ( $\mu \mathrm{g} . / \mathrm{ml})$

$\begin{array}{llr}\text { Broth Culture } & = & 1.0 \\ 95 \% \text { Human Serum } & = & 4.0 \\ \text { Loss of Activity } & = & 75 \%\end{array}$

Total $\quad$ Protein-bound fraction $=75 \%$ Penicillin $\left\{\begin{array}{l}\text { Pree (active) fraction }=25 \% \\ \text { F }\end{array}\right.$
It will be seen that in the presence $95 \%$ human serum this penicillin loses some $75 \%$ of its activity compared with the figure obtained from broth culture. This los $\$$ of activity is due to the reversible binding of a proportion of the penicillin to the serund proteins. Bound penicillin is inactive and in th@ example shown in Table $I$, only approxi通 ately $25 \%$ of the penicillin remains in the free (active) form.

Many antibiotics lose activity in the prese of serum and in the case of penicillins, there good correlation between the loss of activity in $95 \%$ human serum and the degree of protein binding.

The minimum inhibitory concentrations of an antibiotic generally published for a range of organisms are those obtained from broth culture and there is often inadequate informa tion about the extent or effect of protein binding.

Consideration of the minimum inhibitory concentrations of a penicillin obtained from broth culture in conjunction with serum concentrations following a given dosage can be్ very misleading; for the methods usually employed to determine the serum concentrations of a penicillin give only total serum level, thap is to say, the figure so obtained refers to the sum of the free and protein-bound fractions $N$

Estimations of total serum levels of the penicillin are shown in Table II and Figure 1요 If the total serum concentration curve (Fig. 1) is considered in relation to the M.I.C. for the organism obtained in broth culture, it wiff be seen that the serum level exceeds thes M.I.C. for almost 4 hours; but if the M.I.C. obtained in the presence of $95 \%$ of 


\section{TABLE II}

Serum Concentrations of Total Penicillin (Free and Protein-bound)

Serum Concentrations ( $\mu \mathrm{g} . / \mathrm{ml}$.)

$\frac{1}{2} \mathrm{hr} .1 \mathrm{hr} .2 \mathrm{hr} .4 \mathrm{hr} .6 \mathrm{hr}$.

$\begin{array}{llllll}\text { Total Penicillin } & 8 & 4 & 2 & 1 & 0.2\end{array}$

human serum is considered, then the level exceeds the M.I.C. for only 1 hour.

The clinical significance of this will be readily appreciated if one considers the example of septicæmia where both organism and penicillin are present together in the plasma (serum). Under these circumstances, it is obvious that the M.I.C. in 95\% human serum should be considered in relation to the serum concentration curve and not the M.I.C. obtained from broth cultures.

Alternatively, we may relate the concentration of the free fraction of penicillin in the serum to the M.I.C. in broth for this takes into consideration the degrees of proteinbinding (Table III and Figure 2).

\section{TABLE III}

Serum Concentrations of Free Penicillin

Serum Concentrations ( $\mu \mathrm{g} . / \mathrm{ml}$.)

$\frac{1}{2}$ hr. $1 \mathrm{hr} .2 \mathrm{hr} . \quad 4 \mathrm{hr} .6 \mathrm{hr}$.

$\begin{array}{llllll}\text { Free Penicillin } & 2 & 1 & 0.5 & 0.25 & 0.05\end{array}$

In the example cited, the free fraction is approximately only $25 \%$ of the total serum concentration at any given time.

It will be seen that the relationship of the free fraction of penicillin to the M.I.C. in broth culture is the same as the relationship of total penicillin to the M.I.C. in $95 \%$ human serum.

Now, the loss of activity of a penicillin in the presence of $95 \%$ human serum gives only an approximate value for the degree of proteinbinding and more precise methods of determining the free fraction are described below.

An approach often considered to give a more reliable assessment of therapeutic potential is the determination of the so-called antibacterial activity of serum following a given dose of antibiotic; the subject's serum being serially

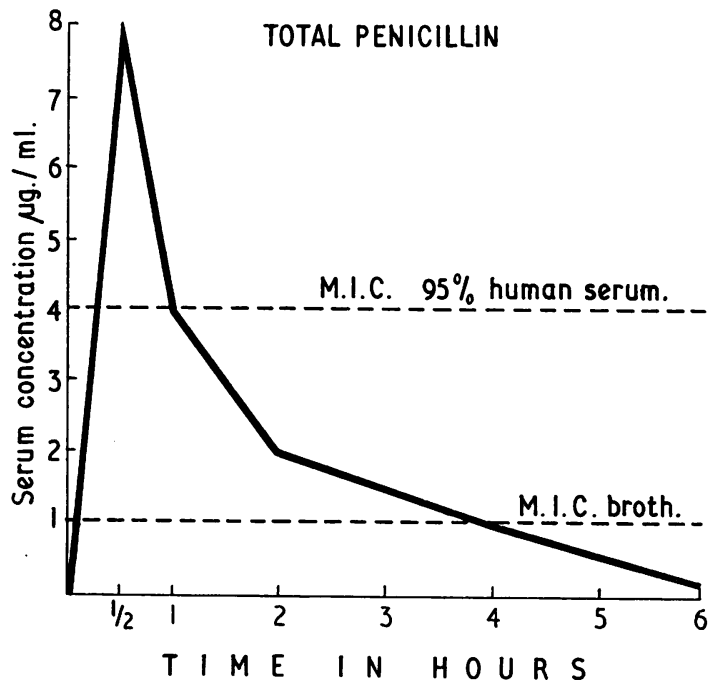

FIG. 1.-Total penicillin concentration and M.I.C. value in broth and $95 \%$ human serum.

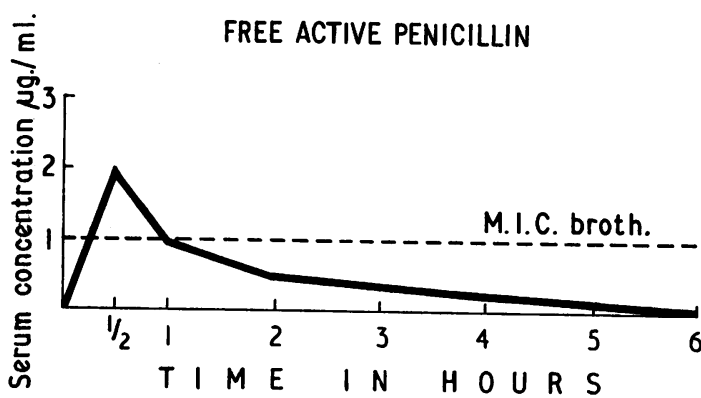

FIG. 2.-Free (active) penicillin concentration and M.I.C. value in broth.

diluted to the point where it will just inhibit the growth of the test organism. Unfortunately, here again, the figure can be misleading as the necessary serial dilutions are usually made with buffer and at dilutions of $1: 100$ or greater, the protein-binding effect has been virtually negated since the original serum has now been diluted to $1 \%$ or less. The binding of penicillin to protein is, in general, a loose one and dilution with buffer lowers the protein concentration of the resulting solution so that the protein-bound penicillin is liberated in a free (active) form. The final inhibitory dilution obtained in this way, therefore, certainly does not give the true antibacterial activity of the 
original undiluted serum; to obtain this figure, the dilutions should have been made, not with buffer, but with human serum.

The importance of the free fraction of an antibiotic cannot be overstressed, I have merely cited the case of septicæmia where this must obviously be so, but there is evidence, described by Dr. G. N. Rolinson on page 18 to support the hypothesis that the free fraction of penicillin (or indeed, any antibiotic) in any body tissue is virtually equal to the free fraction in the serum at any given moment since this fraction can diffuse readily between serum and tissue fluid. However total penicillin level in the tissues may be greater or less than the total penicillin concentration in the serum depending upon the nature and concentration of the protein in the tissue fluid.

It is often suggested that serum concentrations are of little importance and it is the "tissue" concentrations that are of greater value. In actual fact, figures quoted for "tissue" concentrations are usually obtained by homogenising a known weight of tissue, extracting with buffer and assaying the penicillin in the extract against a buffer standard. Now this procedure measures total tissue penicillin only. Even this figure, however, is an incorrect one for the concentration and nature of any protein present in the tissue extract has not usually been taken into consideration from the point of view of the standard used in the determination. This total penicillin level, irrespective of accuracy, gives no information whatsoever regarding the relationship of the free to bound fraction present originally in the tissue fluid. In fact the measurement is a composite one depending among other factors, upon the vascularity of the tissue since the greater the vascularity of the tissue, the greater will be the penicillin contribution from the serum during homogenisation.

Renal "tissue" concentrations are often quoted for poorly absorbed antibiotics with poor serum levels, for here the antibiotic may be well concentrated in the urine to the extent of many hundreds of $\mu \mathrm{g} . / \mathrm{ml}$. The residual urine extracted during the original homogenisation process gives falsely high total antibiotic levels, and it is often incorrectly concluded that although the serum concentration of the antibiotic is low it nevertheless has "great affinity for the kidney".

There are problems, therefore, in the interpretation of the results of these so-called "tissue" concentration determinations and it is very doubtful if they are of any real siğ nificance.

It might be considered that in vivo investiga-tions in animals serve as a better guide to: therapeutic potential in man than in vitr\& studies. Chemotherapeutic assessment is ofter carried out in suitably infected animals wit? the determination of the $\mathrm{CD}_{50}$ value (the dose that will protect half the animals treated).

A critical examination of the investigatiofp exposes a number of fallacies. If the antibio $\overrightarrow{0}$ tic is intended for oral use in man, then orat absorption in the test animal can be quite different from that of man. The use of the parenteral route, however, will overcome the problems of oral absorption but it is essential to know the serum concentration of the antis biotic obtained in the animal so that a realistie comparison can be made with man. To obtai an accurate serum concentration in the animat experiment, the standard must be prepared in the serum of the test animal, otherwise the figure obtained will again be an erroneous one Even if this precaution is observed, the estima tion is still only one of total serum penicillip and unless the degree of protein-binding in animal serum is known, then the all importßnt free fraction cannot be calculated. Proterine binding in animal sera is quite different frô that of man. For example, two penicillins and $B$ may be equally active, equally well ab옹 sorbed and equally protein-bound, giving as near as possible, equal $C_{30}$ values in the test animal. In man, however, A may be highly: protein-bound in human serum and $B$ less so It might also be found that $A$ is poorly ab옥 sorbed and $B$ well absorbed in the human For both these reasons $B$ is obviously the more useful therapeutic agent in man, although they appeared equal in animal studies.

It is important to appreciate that anima chemotherapeutic studies merely select the best. compound for the treatment of the infection in the test animal and are not necessary a true guide to man. Results obtained in mice which show superior $\mathrm{CD}_{50}$ values for an antibiotic in (say) streptococcal infections certainly canno을. be directly translated to man.

It would appear, then, that the vast majority of laboratory data usually presented in relation ${ }^{\circ}$ to the properties of antibiotics require carefulw interpretation and much of it is of very doubtful value.

The final investigation for therapeutic assessment is the clinical trial in man. This again is not without problems. It is relatively easy to 
demonstrate a chemotherapeutic effect of a compound that has a reasonable degree of activity against a certain pathogen, particularly if the dosage used in the trial is high enough to provide adequate free antibiotic levels in serum and tissues. Unfortunately, with so many new antibiotics at our disposal, it is extremely difficult to show clinically that one effective antibiotic is in fact better than another effective antibiotic and if comparison is to be made, very large numbers of patients are required for it is not possible to carry out a comparitive trial at threshold dosages when treating active human infections.

\title{
ESTIMATION AND USE OF SERUM LEVELS IN THE EVALUATION OF THE NEW PENICILLINS
}

\author{
J. M. BoND \\ National Institute for Medical Research, Mill Hill, London, N.W.7.
}

PENICILlins are reversibly bound to serum albumin, and in their bound form are biologically inactive, although the activity is not destroyed and can be recovered by dissociation of the antibiotic/protein complex. Whatever its therapeutic significance, this binding of penicillins is important when assaying serum levels, especially when these results are to be used to compare by laboratory tests the possible efficacy of different penicillins. Assay results estimating the quantity of antibiotic in a serum will depend on the technique used, therefore it is important to know and to state exactly what is being estimated in an assay, whether it is the free (unbound) antibiotic, or the total antibiotic present in both forms, or something between these two. The more precise the result needed, the more necessary it is to have an exact measurement of the extent of the binding.

The assay of total antibiotic in a sample can be achieved by using an assay standard in exactly the same diluent as the sample. In the case of serum levels, standard in homologous serum will give an exact estimate of all the antibiotic present in that particular serum.

The assay of free, unbound antibiotic depends on the use of some method of separating the serum protein with its bound penicillin from the aqueous phase, without further dissociating the penicillin/albumin complex. We have used a method of filtration under negative pressure through dialysis membrane. Controls showed that no protein went through the membrane, and secondly that there was no differential filtration of the antibiotic itself, as occurred with certain other similar techniques.

When comparing penicillins, two sources of variation in serum binding have to be con sidered. Firstly there is the well-known varia tion in percentage binding between different penicillins to the same medium. Table I shows a series of results using bovine albumin. Total antibiotic was the quantity added, and the free level was measured by the filtration technique just mentioned. It seemed useful to have a series of penicillins all estimated by the same technique, frequently the results from different laboratories are compared but if they are using different techniques, they may not be measuring the same fraction, therefore conclusions may be incorrect. Bovine albumin

TABLE I.

Percentage Binding of Penicillins to Bovine Albumin

\begin{tabular}{lccc}
\hline \multicolumn{1}{c}{ Antibiotic } & $\begin{array}{c}\text { Bovine } \\
1 \%\end{array}$ & $\begin{array}{c}\text { Albumin } \\
5 \%\end{array}$ & $\begin{array}{c}\text { Human } \\
\text { Serum }\end{array}$ \\
Ampicillin & 14.4 & 21.2 & \\
Benzylpenicillin & 36.2 & 71.5 & \\
Methicillin & 39.9 & 63.3 & \\
Phenoxymethyl & & & \\
$\quad$ penicillin & 49.7 & 84.3 & 80.1 \\
Oxacillin & 55.8 & 82.4 & \\
Phenethicillin & 60.2 & 86.7 & 75.2 \\
Propicillin & 82.9 & 94.3 & 89.3 \\
Phenbenicillin & 93.0 & 98.1 & 97.2 \\
\hline
\end{tabular}

